\title{
Author/Subject Indexes Vol. 43, No. 1-2, 1997
}

Adams, C. 8 Aisen,P.S. 143 Bartholomeus, I.G.P. 67 Beyreuther, K. 119 Bosman, G.J.C.G.M. 67 Cowburn,R.F. 132 Dahlström,A. 95 DeGrip,W.J. 67 De Teresa, R. 109 Fowler, CJ. 132 Goodman, J. 44 Joseph, J A. 132 Kang,D. 109 Kay,M.M.B. 1,44 Lesnikov, V. 20 Ling,E.A. 95 McRae,A. 95 Mallory,M. 109 Masliah,E. 109 Masters, C.L. 119

Mönning, U. 119 Pierpaoli,W. 20 Renkawek, K. 67 Saitoh, T. 109 Sandbrink,R. 119 Singh, V.K. 79 Torre, J.C. de la 26 Van Workum, F.P.A. 67

Subject Index Vol. 43, No. 1-2,1997

Ag(e)ing 20, 67, 79 Alternative splicing 119 Alzheimer's blood test 44 - $\quad$ disease 8, 26, 67, 79, 95, 109,

$119,132,143$

Amyloid 8,95

- $\quad$ precursor-like protein 119

ß-Amyloid 132

BA4-Amyloid protein precursor

119 Anion transporter 67 Anti-inflammatory drugs 143 Apolipoprotein E 8, 109 APP 8

Astrocyte 109 Autoimmunity 79 Brain capillaries 26

Cell death 67

Cell-mediated immunity 79 Cerebral blood flow 26 Cerebromicrovessels 26 Chondroitin sulfate glycosamino-

glycan 119 Dementia 26 Diagnosis 95 Differential isoform expression

119 Glia 8 Gliosis 109 Glucocorticoids 143 Glucose/oxygen 26 Human monoclonals 44 Immune mechanisms 95 Inflammation 79, 143

Membrane 67

Microglia 95, 109

Neuritic plaque 109

Neuroimmunomodulation 20

Neuron(s) 67

-, selective vulnerability 119

Oxidative stress 132

pH 67

Pineal gland 20

Proteoglycan 119

Senescent cell antigen 44

Signal transduction 132

Tau 8

Therapeutics 143

Therapy 95

Transport 44

Ultrastructure 26 
